\title{
FACTORING ENVIRONMENT INTO ELECTRIFICATION MANAGEMENT IN A REGION
}

\author{
L. D. GITELMAN, L. M. GITELMAN \& M. V. KOZHEVNIKOV \\ Department of Energy and Industrial Management Systems, Ural Federal University, Russia.
}

\begin{abstract}
Electrification is an integrated continuous process of production, transmission, distribution and use of electric power in a region's economy. Analysis of global trends shows that demand for electric power as the most advanced and flexible energy carrier has been growing as many countries are in transition to a new industrial landscape. Along with that, the energy provision of industrial and domestic processes is becoming more intellect-intensive, while environmental issues are receiving special attention. This determines the relevance of the study.

The authors have designed a methodology for factoring the environment into regional electrification programs. The methodology includes the following steps: ranking and selecting facilities to be electrified based on the criterion of minimal values of the 'electricity-for-fuel substitution coefficient'; application of the energy and economic effect to financially compensate for environmental impacts; introduction of demand side management programs that help improve the environmental situation in the region.

An 'ideal' structural model of electrification is proposed for regions with high eco-loads. The model combines a method for selecting facilities to be electrified, pro-active energy conservation, adding more energy installations utilizing carbon-neutral fuels to the power generating system.

Keywords: demand side management, ecology, electrification, energy intensity, fuel for direct firing, fuel replacement, region.
\end{abstract}

\section{INTRODUCTION}

The demand for electricity is shaped by complex interconnections between the conditions and pace of the development of the economy and the energy sector, objectively existing trends and various factors (infrastructure of energy markets, the environmental performance and economic effectiveness of power generation technologies, the level and transparency of tariffs, flexibility of the tariff range and the development of distributed generation $[1,2]$ ).

Some experts believe that the growing demand for electric power that shows in the spread of 'smart' electrification of national economies and regions is one of the contemporary megatrends that create a new power reality $[3,4]$. However, the issue of electrification in countries whose regions differ considerably in energy and economic conditions (natural and mineral resources, climate, the structure of industrial production and electricity generation capacity, environmental pressure) have not been studied sufficiently. This applies to a framework of definitions; measures of electrification; evaluations of its effectiveness at the national, regional and business levels; and inter-relations with environmental protection activities.

An analysis conducted by the authors shows that scholars internationally focus primarily on four aspects of electrification that dominate up to $90 \%$ of all papers published on the subject.

1. Electrification issues in suburbs and rural areas. This implies the decentralization of electricity grids, installation of renewable energy systems, using them as the kernel of 'micro-grids', electrification in agriculture and farm mechanization [5-7].

2. Electrification in Africa, Asia and some Latin American countries. In the next 20 to 30 years the catching-up economies will be hugely attractive as emerging energy markets 
because, taken together, these countries have nearly $900 \mathrm{~m}$ 'potential' electricity consumers. It is quite logical that the issue has been widely investigated by individual scholars as well as by international energy commissions [8-10].

3. Adoption of electric vehicles and electrification of roads. Available studies cover the development of road transport, sea transport and high-speed railway lines. In a wider sense, the subject matter includes the issues of building and retrofitting transportation systems in residential and commercial buildings (elevators, escalators, lifting systems etc.) [11, 12].

4. Electrification of buildings through the design and construction of 'smart' facilities that produce their own power, thus entirely meeting their own energy needs, including electricity and heat, by employing cutting-edge organizational and technological solutions. Scholars note that the trend is driven by the emergence of new materials for power installations (solar panels, batteries, energy storage systems) [13, 14].

The issue of industrial electrification remains the least studied one despite the fact that industrial facilities are the largest consumers of electricity, and various projections indicate that in the short-term and mid-term perspectives the share of industry in overall power consumption will grow further. Consequently, it is the manufacturing sector that will predominately generate the key effects of electrification, the environmental impact being the main one.

\section{PECULIARITIES OF INDUSTRIAL ELECTRIFICATION}

Electrical power is the most advanced and effective energy carrier today, its key assumed advantages over alternatives (such as fossil fuels) being its ability to be converted into any final form of energy; the possibility of ergonomic and precise regulation of technological process parameters (that is, the physical and technical characteristics of the final form of energy); a higher intensity of a production process through its abrupt acceleration and zero pollution at the final utilization stage.

If we proceed from this assertion, industrial electrification could be defined as the introduction and uptake (to the level of saturation) of production and technological machines in which electricity replaces alternatives (competing energy carriers) and generates more advanced final forms of energy, or is the only (technologically) possible energy carrier for the final form of energy and the production purpose (function) of a certain technology. The definition indicates the forms of electrification, that is, the functions of electrical power in the process. If we bear in mind that any technological innovation today is in fact an electricitybased technology, we could state that electrification is not an isolated trend in technological progress, but its universal energy basis, that is, technological progress from the energy perspective $[15,16]$.

Industrial electrification could be pervasive (if there is considerable potential for electrical power use), especially if it takes place as part of a government-sponsored program of a technological revamp. At the same time, in some industries as well as at some companies electrification can be an in-house project launched under the pressure of competition. In this case, electrification is discretely distributed over time and space.

The wave-like dynamics and discreteness of electrification as a process shows that it goes through several development stages that differ in their priority forms and directions: machines replacing manual labor, electricity-based technologies that utilize innovative final forms of energy (e.g. replacing mechanical processing and conventional electrothermic processes in metal processing) and information technology for manufacturing production management. 
The prospects of a new stage of electrification depend, of course, on the cost of electricity supply. In a favorable environment that stems from, among other things, growing prices for fossil fuels (natural gas) and their limited availability to industrial consumers, one can foresee the following lines in industrial electrification:

- electrothermic processes will completely replace fuel-based high temperature and medium temperature methods of metal processing; some low-temperature processes will begin to be electrified (e.g. heating in some regions);

- the extensive application of electricity-based, physical and chemical materials-processing methods, the level of electrification reaching 50\% across the machine building industry [17];

- pressing processes will be entirely powered by electricity (steam-driven presses and heavy-duty hammers will be phased out);

- new-generation intelligent electronic automation devices will start to be adopted in various areas of corporate management.

\section{AN OVERVIEW OF GLOBAL ELECTRIFICATION TRENDS}

It is common international practice to use energy intensity and electricity intensity of gross regional product per capita for analyzing electrification trends. These are aggregate indicators, so apart from the level of electrification they also reflect the dynamics of a large number of other factors that are not directly associated with electrification. On other hand, they do not take into account structural shifts that are observed in industry thanks to economic growth; energy conservation trends by energy carrier, the scaling-up of conventional electricity-based technologies in which electrical power is the only monopolistic energy carrier. This leads us to a conclusion that in order to produce a correct assessment one needs to go down to a lower level of technology (energy consuming process) analysis - that of companies with specific functional goals [18].

We will, nevertheless, take a look at some composite indicators that paint a global picture of electrification.

Over the past 40 years the global production of electrical power has increased almost fourfold from 6,287 Twh in 1974 to 23,950 Twh in 2015. At the same time, over the past decade an increase in electricity production and consumption has been driven by developing economies. In China, for example, electricity consumption per capita grew four-fold between 2000 and 2013 - from $990 \mathrm{kWh}$ /year to 3,800 kWh/year [19, 20].

Globally, electricity is largely generated by coal-fired CHP plants. It has to be noted, though, that in OECD member countries coal-fired electricity generation practically matched generation from natural gas in 2015 (Fig. 1).

Industry accounts for around $45 \%$ of electricity consumption, being the largest end user of electrical power. Over the past 10 years there has been observed a steady upward trend in industrial electricity consumption, yet the increase has been lagging behind economic growth. According to some projections, industrial electricity consumption will stabilize in the long term $[19,21,22]$.

It expected that electricity intensity will exhibit mixed dynamics in various industries. In metallurgical production, the share of recycled scrap in production input will grow, which will make it possible to save up to $90 \%$ to $95 \%$ of primary energy, but will increase the electricity intensity of steel making and the aluminum industry. Heavy oil production will also require additional electrical power, thus increasing the energy intensity of the industry [22]. 


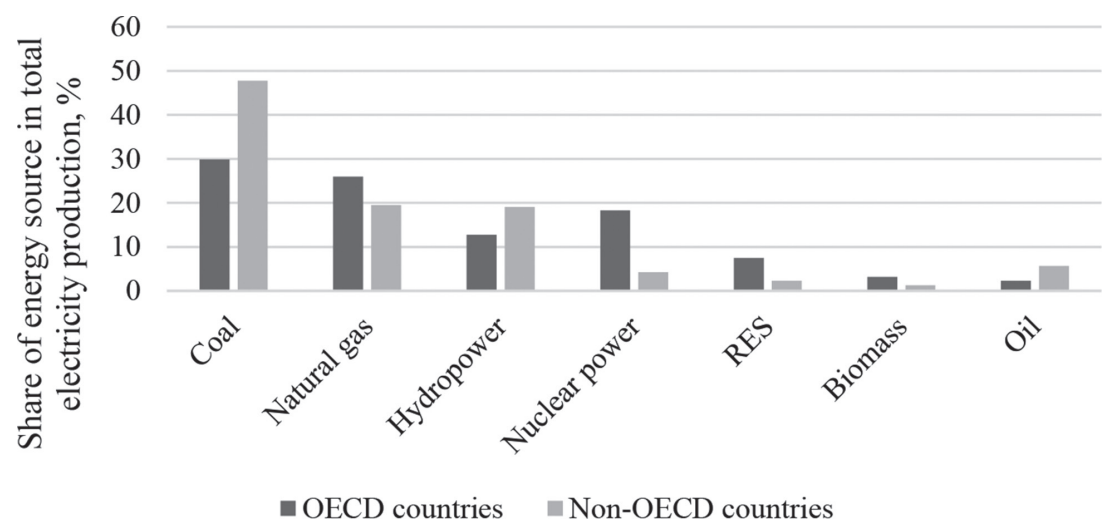

Figure 1: Energy sources used in electrical power production.

The share of electricity in industrial energy consumption in Europe grew from $23 \%$ in 1990 to $32 \%$ in 2014 whereas the share of coal dropped by nearly a half (from $25 \%$ to $14 \%$ ), while that of oil from $15 \%$ to $12 \%$. The share of natural gas dropped from its peak of $32 \%$ in 2001 to $27 \%$ in 2014 . Electricity has therefore become the priority energy source for industry in the twentyfirst century (Figs 2 and 3).

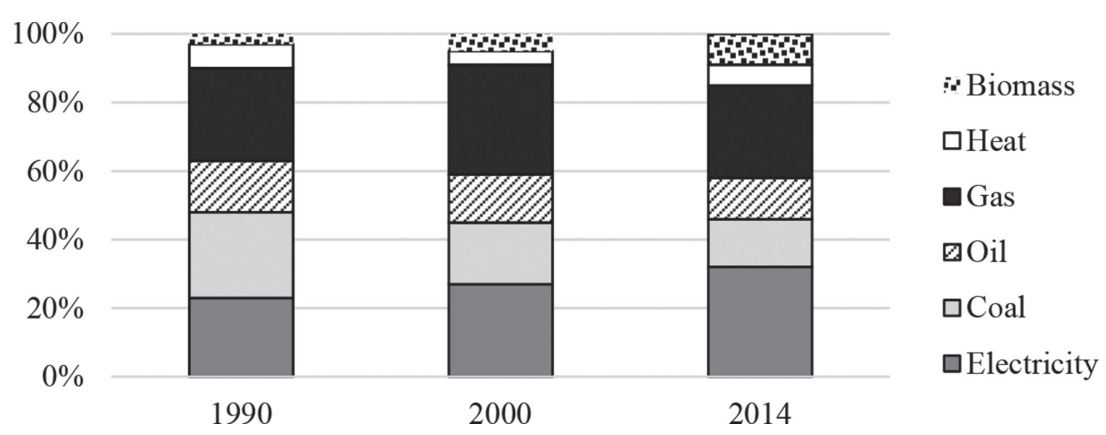

Figure 2: Shifts in the structure of energy sources in Europe's industrial energy consumption.

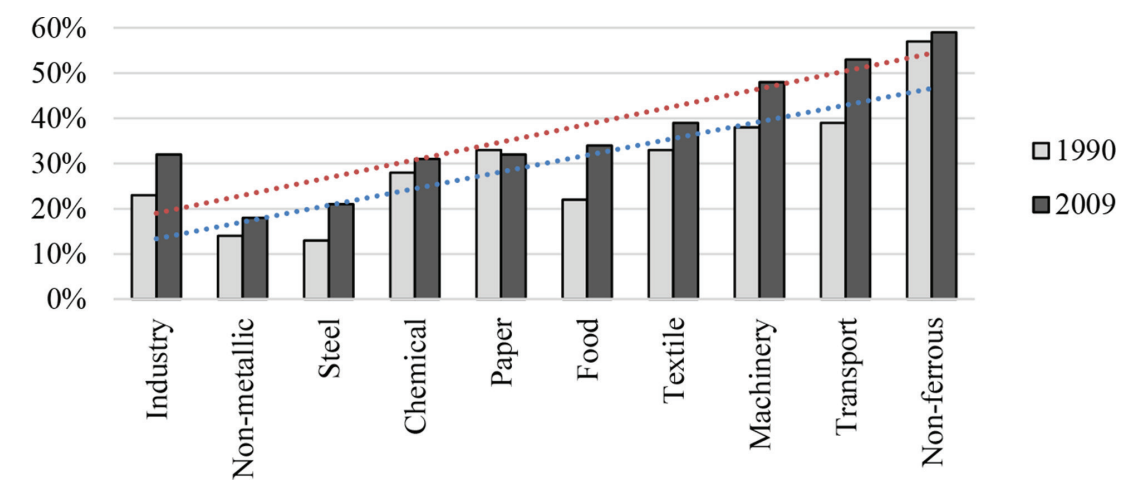

Figure 3: Electrification rate by industrial branch in Europe. 
Four key factors encouraged the penetration of electricity in European industry:

- production processes are becoming increasingly mechanized and automated, especially in countries that implement accelerated technological overhaul programs and establish 'smart' factories;

- fuel and energy resources are being substituted in electricity-intensive production processes (steelmaking, electric furnaces for glass making etc.) due to a faster drop in relative electricity prices as compared to a number of fossil fuels (for example, natural gas), and environmental pressures;

- the transition to a zero-carbon economy following a drastic reduction in fossil fuel uses in manufacturing and by the transport sector;

- a call for higher reliability and flexibility of production [24].

\section{CONTROL OVER THE FACTOR OF ENVIRONMENT WHEN IMPLEMENTING REGIONAL ELECTRIFICATION PROGRAMS}

The penetration of electricity leads to stronger impacts of electricity production on the environment. The impacts are extremely versatile and are to a large extent determined by the type of the electrical generator (Fig. 4).

As stated above, heat and power plants account for the major share of electricity production today. It is, therefore, CHP plants that need to be looked at when examining the negative impact of electrical power generation on the biosphere as they consume around a third of all fossil fuels extracted in the world. For example, a 2,400-MW CHP plant burns coal at a rate of 1,000 tons per hour and oxygen at a rate of 1,600 tons per hour. Emissions generated by the plant equipped with electrostatic precipitators (99\% efficiency) amount to 2,300 tons per hour of $\mathrm{CO}_{2}, 250$ tons per hour of water, 34 tons per hour of $\mathrm{SO}_{2}, 2$ tons per hour of fly ass and 35 tons per hour of solid residue [25].

Environmental improvements brought about electrification through the substitution of electricity for primary fuels are essentially of regional scale; they are felt in electricity consumption and depend on the following:

- the volume of nominally substituted fuel at facilities being electrified in the region (within the energy system);

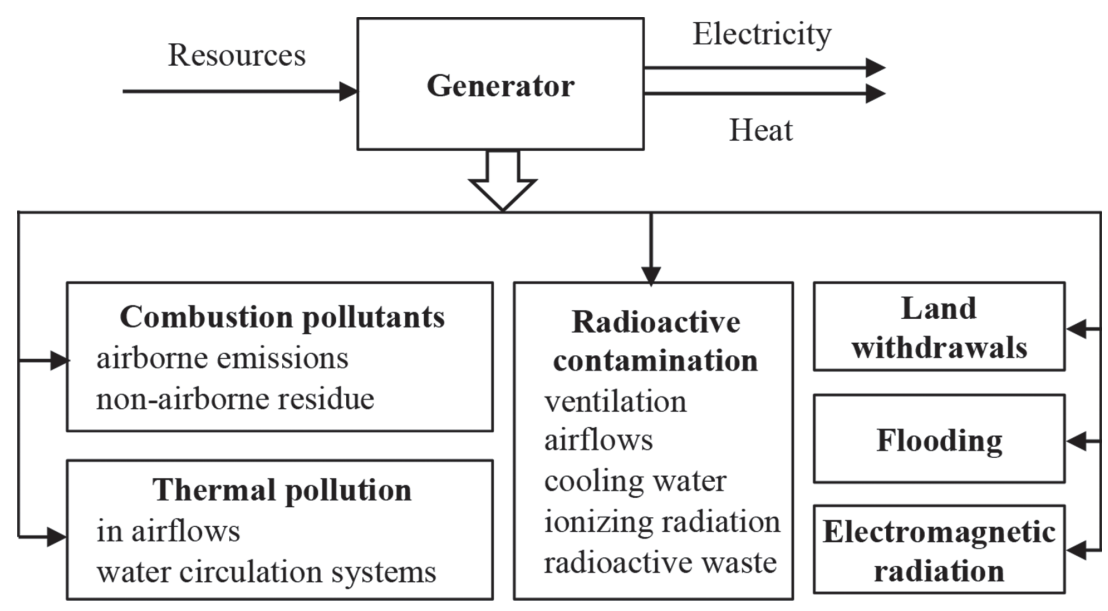

Figure 4: Main environmental impacts of electricity generation. 
- environmental attributes of the fuel being replaced;

- the efficiency of pollution reduction systems in the fuel-burning case;

- the composition of pollutants in exhaust gases after passing through pollution-reduction systems.

The positive environmental effect in electricity consumption is countered by additional environmental impacts of electricity generation (especially if electricity is supplied by CHP plants). The impacts may show in the regions where the facilities being electrified are located, as well as in neighboring regions if cross-regional supply of electric power cannot be increased (due to restrictions on the commissioning of additional capacity in the regions being electrified). The environmental impact of electricity generation can be offset by environmental improvements provided by electricity use only if the composition of pollutants is identical in both cases and if the pollution dispersion areas overlap.

This is the reason why the focus is on the global mitigation of the above mentioned negative environmental effects of electricity generation (primarily by CHP plants), rationalizing demand for additional electricity being a possible solution.

As their contribution to the subject, the authors propose an 'electricity-for-fuel substitution coefficient $\left(C_{\text {sub }}^{e f}\right)$ ' that could serve as a key indicator combining electricity production and consumption. The coefficient indicates the amount of electricity expressed in kilowatt hour that is required for replacing a ton of reference fuel at a given facility being electrified that operates in its optimal mode (or in a certain technological process or fuel-fired unit). The coefficient takes into account the difference in the energy efficiency of the fuel-burning and electricity-powered units and their performance modes.

$$
C_{s u b}^{e f}=\frac{\Delta E}{\Delta F},
$$

where $\Delta E$ is the volume of electricity ( $\mathrm{kWh}$ ) that supplied for replacement of fuel in the calculation period; $\Delta F$ is the volume of the substituted fuel (tons of fuel equivalent) at facilities being electrified over the calculation period.

Standard $C_{\text {sub }}^{e f}$ values should be enforced to be met by individual typical facilities switching over to electricity in order to build a legal framework for industrial electrification as part of a state-sponsored targeted development program. In this regard, it is important that the minimum values of the coefficient are used to select and rank potentially efficient regional facilities subject to electrification.

Another integration activity that is being implemented in the field of consumption is allaround energy conservation in installations, devices and equipment that are powered exclusively with electricity (electric motors, lighting, some production electric technologies etc.).

In the field of electric power generation, it is expedient to adopt the following environmental protection solutions (that meet established standards at the very least);

- to minimize per-unit fuel consumption or increase the energy efficiency of power generating units (for example, by building gas turbine cogeneration plants);

- to use greener fuels;

- to use environmentally advanced technologies of fuel combustion in boiler plants;

- to fit highly efficient filtration systems to power units.

The unit capacity of power installations and power plants is a separate question. From the point of view of chronological synchronization (agreeing the time of the construction of the 
facility being electrified with the time of putting energy capacity into service), reliability and efficiency as well as flexibility, preference should be given to small and mid-size plants with an efficiency exceeding $80 \%$ and advanced environmental attributes that are achieved, above all, through the use of specially designed fuel combustion technologies.

When a region is faced with additional environmental impacts that significantly aggravate the overall environmental situation there and cannot be fully offset with the help with the organizational and technical methods described above, the issue arises of offering targeted compensation payments to the region suffering from the negative externalities. No provisions might be made for such compensation payments if environmentally efficient generation solutions are in place and the cumulative environmental effect is positive (when comparable types of pollutants are considered).

Compensation might be envisaged for neighboring regions, too, when they have additional generation capacity, but do not have their own efficient facilities to be electrified (these are often regions that already deal with severe environmental impacts, see Figs 5 and 6).

The economic effect of electrification can provide a source for such compensation. The effect is equivalent to the monetary value of the replaced fuel that increases the national energy reserves. The monetary value of the effect is not equal to the price of the fuel being utilized before its replacement with electricity; the value is determined by the national goals of using the newly available resources domestically and for export. It is assumed that the resources will be utilized more efficiently than before, when they were burnt as fuel for boilers and furnaces.

When designing an organizational and economic mechanism of electrification, especially in regions with high environmental pressures, priority should be given to the possibility of

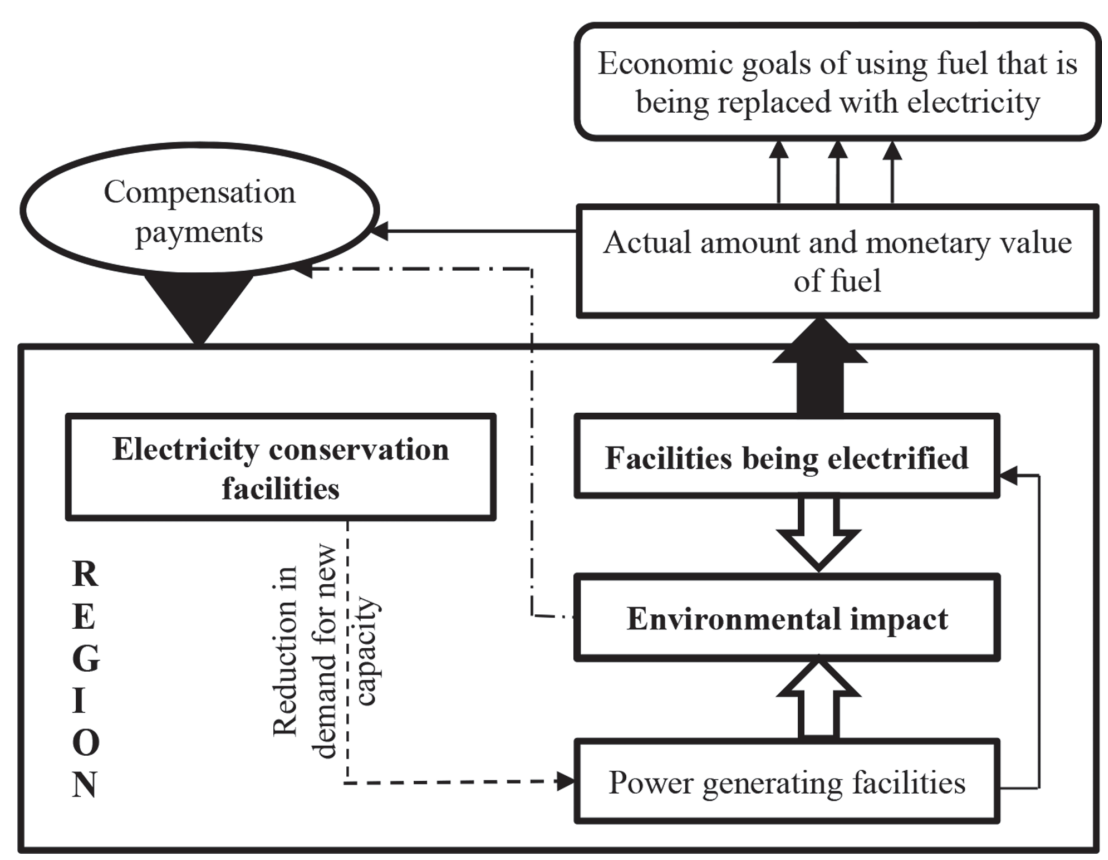

Figure 5: A fundamental layout of energy, environmental and economic interconnections within the electrification system of a region that has sufficient generating and grid capacity. 


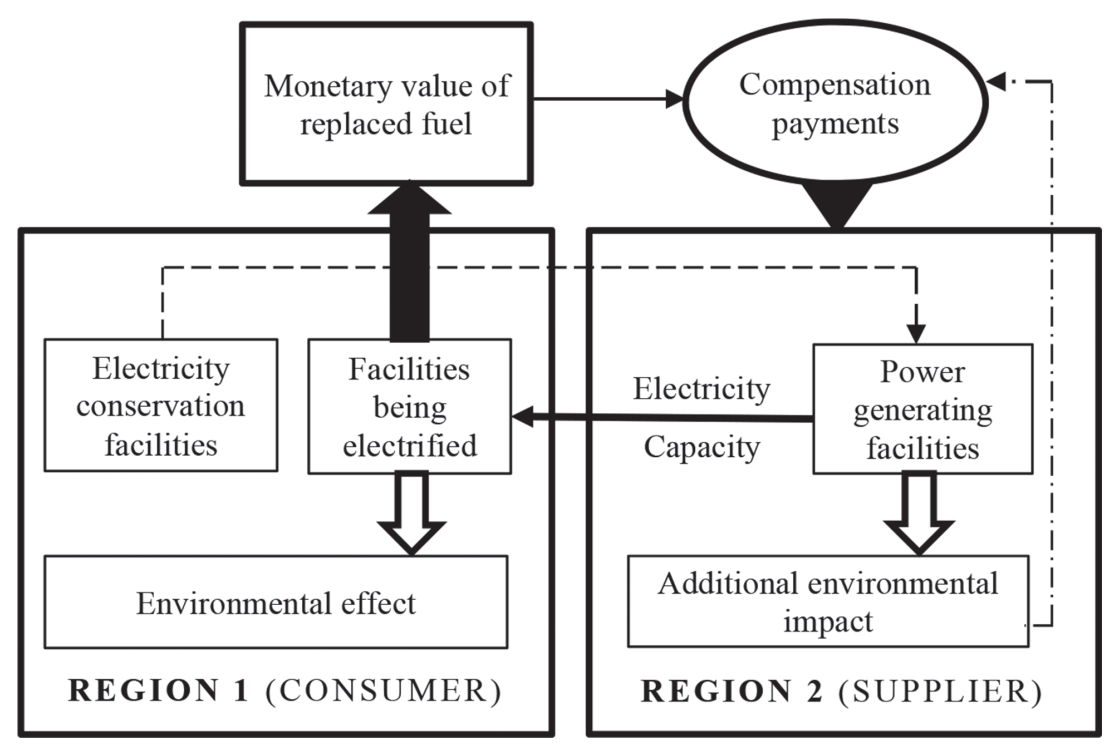

Figure 6: A fundamental layout of energy, environmental and economic interconnections between the consuming region (beneficiary of environmental improvements) that has a shortage of capacity, and the supplier region that suffers from additional environmental impacts.

developing a structure of generating capacity based on small hydro, RES as well as small and medium nuclear power reactors supplemented with gas-powered CHP turbines with maximum energy and environmental efficiency characteristics.

Finally, we would like to repeat that, being a process of interaction between electricity consumers and suppliers, electrification generates mixed environmental effects. At the

Table 1: Influence of environmental impacts in a region on electrification.

Contribution to air

pollution in the region

\begin{tabular}{|c|c|c|}
\hline Industry & $\begin{array}{l}\text { Electricity } \\
\text { generation }\end{array}$ & Possible solutions through change in electricity consumption \\
\hline $\begin{array}{l}\text { High } \\
\text { (over 30\%) }\end{array}$ & $\begin{array}{l}\text { High } \\
(15 \%-20 \%)\end{array}$ & $\begin{array}{l}\text { - Development of electrothermal technology with medium } \\
\text { electricity intensity and minimum electricity-for-fuel } \\
\text { substitution coefficient' } \\
\text { - Increasing energy efficiency and rationalization of loads }\end{array}$ \\
\hline $\begin{array}{l}\text { Low (less } \\
\text { than } 10 \% \text { ) }\end{array}$ & $\begin{array}{l}\text { Low (less } \\
\text { than } 10 \% \text { ) }\end{array}$ & $\begin{array}{l}\text { Development of electricity-based technology with the single } \\
\text { electricity-intensive energy carrier and lesser standards for } \\
\text { electricity-for-fuel substitution coefficient. }\end{array}$ \\
\hline High & Low & - Development of electricity-intensive electrothermic technology \\
\hline Low & High & $\begin{array}{l}\text { - Increasing energy efficiency and rationalization of loads } \\
\text { - Development of electricity non-intensive technologies with } \\
\text { electricity-for-fuel substitution coefficient }\end{array}$ \\
\hline
\end{tabular}


end-use stage, electricity is a zero-pollution energy carrier, whereas electric power generation causes additional environmental pressures in the hosting region. It is therefore necessary to pay attention to ensuring the environmental efficiency of the developing (through electrification) electric power industry, especially when it comes to electric power production by power plants (see Table 1).

\section{CONCLUSION}

The key problem that has to be addressed when drafting electricity supply and electrification programs is the creation of a framework of application standards and estimates that must factor in the environment. In this regard, the authors have set out the agenda for further research that they propose for discussion to the global academic community.

1. Assessment and classification of regions in terms of the structure of environmental pressures by sector (electric power production, manufacturing production, transport). Expected outcomes include the analysis of factors that determine the structure of emissions; ideas for reducing emissions by power-generating facilities in environmentally distressed regions.

2. Comparison of distributed heat generation units with traditional large-scale heat and power plants in terms of their environmental performance. Outcomes: assessments of relative airborne emission rates expressed in units of weight per $1 \mathrm{~kW}$ of installed capacity at different generators utilizing similar fuels.

3. Modeling of the environmental consequences of replacing fuel with electricity in industry and taking into account additional environmental pressures in the regional electric power sector (heat and power plants being prevailing generators). The testing region is selected on the grounds of potential for electrification, prevalence of heat and power plants in the structure of generating capacity etc. The study will make it possible to determine emission growth caused by power-generating facilities when 1 ton of fuel equivalent is replaced with electricity over a certain period of time (month, three months, year); a decrease in emissions generated by industrial facilities when 1 ton of fuel equivalent is replaced with electricity.

4. Comprehensive assessment of the impact of incorporating renewables in the structure of generating capacity (depending on the nature and climate profile of the region) on the environmental performance and efficiency of the local electric power sector. Outcomes: an assessment of the reduction in emissions per $1 \mathrm{~kW}$ of installed capacity of the region's power plants (energy system); assessment of the dynamics of the cost of production of $1 \mathrm{kWh}$ of electricity supplied to the grid by the power plants of the region; estimation of pollution charges paid by power plants; identification of a compromise environmental and economic variant of the generating capacity structure.

5. Testing the hypothesis that energy conservation reduces the demand for generating capacity and mitigates the environmental impact of the electric power sector by carrying out applicable calculations and conducting appropriate analysis for a group of selected testing regions.

\section{ACKNOWLEDGMENT}

The work was supported by Act 211 Government of the Russian Federation, contract No 02. A03.21.0006. 


\section{REFERENCES}

[1] Rostow, W.W., The Stages of Economic Growth: A Non-Communist Manifesto. Cambridge: Cambridge University Press, p. 272, 1960.

[2] Anisimov, S.P. \& Huzmiev, I.K., «Green economy» and power industry [in Russian]. National Projects, 6, pp. 4-13, 2013.

[3] Technology Outlook 2025 - The 10 technology trends creating a new power reality. Arnhem: DNV GL, p. 16, 2016.

[4] Coping with the Energy Challenge. The IEC's role from 2010 to 2030. Smart electrification - The key to energy efficiency. White Paper, International Electrotechnical Comission, 2010. Available at: http://www.iec.ch/smartenergy/pdf/white_paper_lres.pdf. (accessed 12 January 2017).

[5] Baldwin, E., Brass, J.N., Carley, S. \& MacLean, L.M., Electrification and rural development: issues of scale in distributed generation. WIREs Energy and Environment, 4, pp. 196-211, 2015.

https://doi.org/10.1002/wene.129

[6] Kirchhoff, H., Kebir, N., Neumann, K., Heller, P.W. \& Strunz, K., Developing mutual success factors and their application to swarm electrification: microgrids with $100 \%$ renewable energies in the Global South and Germany. Journal of Cleaner Production, 128, pp. 190-200, 2016.

https://doi.org/10.1016/j.jclepro.2016.03.080

[7] Singh, R., Wang, X., Mendoza, J.C. \& Ackom, E.K., Electricity (in) accessibility to the urban poor in developing countries. WIREs Energy and Environment, 4, pp. 339-353, 2015.

https://doi.org/10.1002/wene.148

[8] Addressing the Electricity Access Gap/Background Paper for the World Bank Group Energy Sector Strategy, 2010. Available at: http://siteresources.worldbank.org/EXTESC/Resources/Addressing_the_Electricity_Access_Gap.pdf. (accessed 12 January 2017).

[9] Goldthau, A. (ed.), The Handbook of Global Energy Policy, Oxford: John Wiley \& Sons Ltd, p. 566, 2013.

[10] Cholez, C., Trompette, P., Vinck, D. \& Reverdy, T., Bridging access to electricity through BOP markets: between economic equations and political configurations. Review of Policy Research, 29(6), pp. 713-732, 2012. https://doi.org/10.1111/j.1541-1338.2012.00590.x

[11] Creating the Clean Energy Economy. Analysis of Electric Vehicle Industry, International Economic Development Council, 2013, available at http://www.iedconline.org/ clientuploads/Downloads/edrp/IEDC_Electric_Vehicle_Industry.pdf

[12] Huber, P.V., Broadband electricity and the free-market path to electric cars. Energy Policy and the Environment, 7, 2011, available at http://www.manhattan-institute.org/ pdf/eper_07.pdf

[13] Quiggin, D. \& Buswell, R., The implications of heat electrification on national electrical supply-demand balance under published 2050 energy scenarios. Energy, 98, pp. 253-270, 2016. https://doi.org/10.1016/j.energy.2015.11.060 
[14] De Groote, M. \& Fabbri, M., Smart buildings in a decarbonized energy system. Buildings Performance Institute Europe, 2016. Available at: http://www.eurima.org/uploads/ ModuleXtender/Publications/156/BPIE_Broch-10-principles_160624.pdf. (accessed 12 January 2017).

[15] Ratnikov, B.E., Management of Regional Electrification [in Russian]. Ekaterinburg: USTU-UPI, p. 50, 1994.

[16] Beschinskii, A.A. \& Kogan, Yu.M., Economic Issues of Electrification [in Russian]. Energoatomizdat: Moscow, p. 432, 1983.

[17] Electrification of Chemical Industry. An Opportunity for the Chemical and Electricity Sector. Available at: https://www.tno.nl/media/5813/electrification_of_chemical_ industry.pdf. (accessed 12 January 2017).

[18] Lescaroux, F., Industrial energy demand, a forecasting model based on an index decomposition of structural and efficiency effects. OPEC Energy Review, pp. 477-502, 2013.

[19] Global Energy Statistical Yearbook 2016. Available at: https://yearbook.enerdata.net. (accessed 12 January 2017).

[20] Key Electricity Trends. Excerpt from: Electricity Information. International Energy Agency, 2016. Available at: http://www.iea.org/publications/freepublications/publication/KeyElectricityTrends.pdf. (accessed 12 January 2017).

[21] International Energy Outlook 2016, U.S. Energy Information Administration. Available at: http://www.eia.gov/forecasts/ieo/pdf/0484(2016).pdf. (accessed 12 January 2017).

[22] Annual Energy Outlook 2013 with Projections to 2040/U.S. Energy Information Administration. Available at: www.eia.gov/forecasts/aeo/pdf/0383(2013).pdf. (accessed 12 January 2017).

[23] Mazurova, O.V., Energy intensity of industry: global trends [in Russian]. Industrial Power Sector, 8, pp. 18-22, 2014.

[24] Understanding the electrification of industrial energy consumption in Europe. Available at: http://www.leonardo-energy.org/resources/808/understanding-the-electrification-ofindustrial-energy-consu-582b2f7dced84. (accessed 12 January 2017).

[25] Gitelman, L.D. \& Ratnikov, B.E., An Effective Energy Company. Olimp-Business: Moscow, p. 544, 2002. 